\title{
Smart Sensing competence for heritage building performance: An Experimental Field Study to Evaluate the Actual Smart Sensing Measurements of Thermal Comfort compared to POE Results.
}

\author{
GEHAN NAGY \\ Department of Architectural Engineering \\ The British University in Egypt \\ El Sherouk City - Cairo Suez Desert Road \\ EGYPT
}

\author{
ESRAA ABDELHADY \\ Department of Architectural Engineering \\ The British University in Egypt \\ El Sherouk City - Cairo Suez Desert Road \\ EGYPT
}

\begin{abstract}
In the past few years, the field of thermal comfort has been using the term smart sensing widely. However, barriers may occur due to the inaccuracy of the data collected by smart sensing. The aim of the paper is to evaluate the thermal comfort of occupied heritage buildings by utilizing post occupancy evaluation (POE) as a tool in addition to smart sensing. The accuracy of the overall evaluation process using POE will be increased. The applicable case study presented in the paper is an office space within a building consider as a heritage building in Downtown Cairo. This paper argues the errors obtained due the inaccuracy of data collected from low-cost smart sensors to provide a list of assumed barriers in order to overcome them. The comparison between a POE study results and the actual thermal measurements results obtained from smart sensors installed to evaluate the office's thermal comfort through evaluating the data collected for temperature and humidity in the period of 6 months during the summer. On the other hand, a questionnaire was taken by the occupants in the office to apply the POE study. Therefore, the results of both the data collected from sensors and the questionnaire from the POE study to determine the barriers caused by lack of accuracy.
\end{abstract}

Key-Words: Post-Occupancy Evaluation; Smart sensors; Thermal evaluation; Data accuracy; Comfort level Received: January 11, 2021. Revised: April 14, 2021. Accepted: May 18, 2021. Published: June 2, 2021.

\section{Introduction}

Evaluating indoor thermal comfort has made a huge difference in energy efficiency and adjusting human comfort levels over the years [1] [2] [3]. Nowadays, smart sensing systems for thermal comfort evaluation have become a popular tool widely used in adjusting the heating and cooling systems efficiency of a building. However, it does bare some technical challenges and uncertainties about how accurate the data is. It is argued that these systems may increase the energy efficiency but the thermal comfort level would decrease causing discomfort to occupants [4]. The American Society of Heating, Refrigerating and Air Conditioning Engineers (ASHRAE) described thermal comfort as "that condition of mind that expresses satisfaction with the thermal environment" [5]. Therefore, in order to be able to fully evaluate the thermal comfort of a building, occupant's feedback and satisfaction is of outmost importance. The feedback obtained from occupants of a building while in use. It is often used to evaluate the performance of new structures once occupied in order to obtain feedback on whether the building is performing as expected or not. In this research, POE is employed as an undemanding tool for evaluating occupants' satisfaction levels with thermal comfort.
The main aim of this research is to investigate the barriers and challenges of using low-cost smart sensors in evaluating thermal comfort through comparing results obtained from both evaluation methods used; data obtained from smart sensors for temperatures and humidity and POE questionnaire.

\section{Problem Formulation}

Throughout the past decade, there has been a major shift in the climate. This Climate Change imposes a huge threat on our built cultural heritage, especially heritage buildings in use. This resulted in heritage buildings not being completely adequate to withstand the current climate, thus affecting the indoor thermal comfort. Therefore, the possible effects of climate change on heritage buildings and on the related indoor climate must be investigated. Many researches was dedicated to study the effect of Climate Change on the building IEQ in general [6] [7] [8] [9], however heritage buildings were seldom the focus of the research. This research focuses on heritage buildings in specific giving that they are the buildings mostly affected by this change. 


\subsection{Case Study History}

The case study adopted is an apartment in a heritage building that was retrofitted into an office space. The office is located in a mixed-use heritage building on the third floor. It belongs to the Cairo Lab for Urban Studies, Training and Environmental Research (CLUSTER)

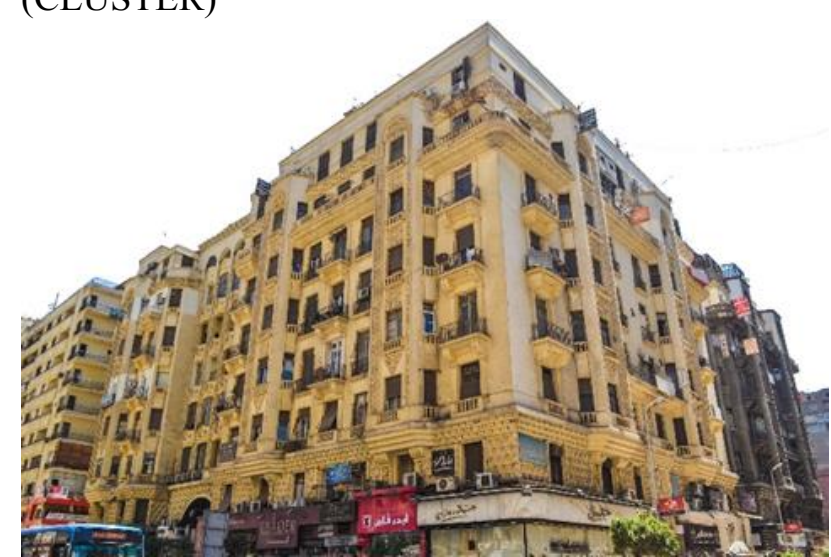

Fig1: Rabbat Building (CLUSTER team, 2017)

The building is located in Downtown, Cairo which is considered the heart of Cairo City. The area dates back to the late 19th and early 20th century and was designed by some of the most prestigious architects in France. They were commissioned by Ismail Pasha during his visit to Paris. The area was once the home of the prosperous elite in Cairo. However, years of neglect followed by Cairo's great fire incident in the 1950's have led to the decay of the building's exterior. The case study building is called 'Rabat'. It was designed by architects Léon Azéma, Max Edrei and Jacques Hardy between 1927-1930. The building is named after the capital city of Morocco.

\section{Problem Solution}

Two methods were applied as analytical approaches to best evaluate thermal comfort within the office space and achieve the research aim. The first method is obtaining readings for temperature and humidity from smart sensors installed in the office space throughout the study period and analyzing the data obtained to indicate thermal comfort level in the office space. The second is a POE survey questionnaire conducted regularly to obtain occupants evaluation about thermal comfort throughout the study period. The POE study questions were oriented towards detecting occupants' satisfaction level with thermal comfort in the studied workplace.

\subsection{Smart Sensors}

Measurements for the thermal condition of the internal environment of the office space were carried out through the installation of low cost sensors which measures the temperature and humidity; Temperature \& Humidity Sensors (PIR). In order to be able to obtain an accurate evaluation of the physical environment, an analysis of how occupants use the space needed to be done in order to identify which spaces are active and which are not as active. This made it possible to take decisions about which rooms need sensors (since there were limitations with number of sensors available). The number of occupants using each space and the frequency of its usage was analyzed in Figure 2.

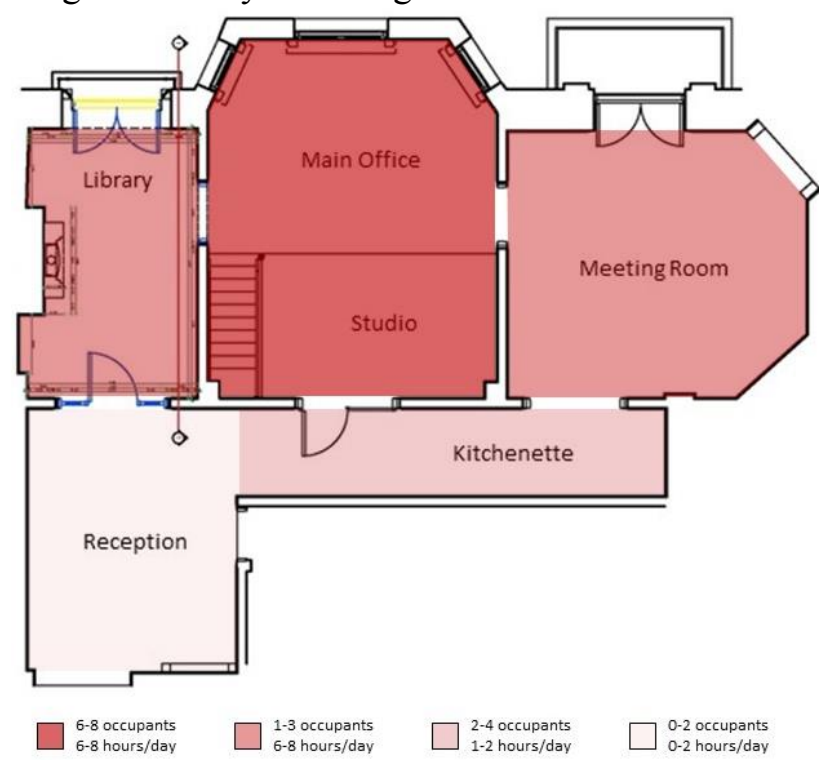

Fig2: Occupant Space-Use Analysis

Sensors were distributed among the office spaces according to the results of the occupant space-use analysis. These sensors were installed and set-up to provide readings every two minutes. In order to obtain accurate results from the sensors, certain specifications for their installation were to be considered. PIRs measure the temperature and humidity, in addition to detecting occupancy movement. Therefore, they had to be installed at an appropriate height that suits human height level in order to be able to detect movement. Hence, PIRs were installed at a range of 1-1.5 $\mathrm{m}$ height. In addition, they had to be installed away from direct sunlight and all other heat gains. Positions of sensors installed on floor plan and samples of how they were installed are represented in Figures 3 and 4.

The data obtained from each sensor is sent to a Monitoring Unit Hub connected wirelessly to the sensors and stored in a Zigbee Dongle USB. The data is then sent to the live website where analysis of this 
data through graphs is possible. Data collected for this paper is of a 6-month sensor period starting from 1st of March to 31st of August, 2017.

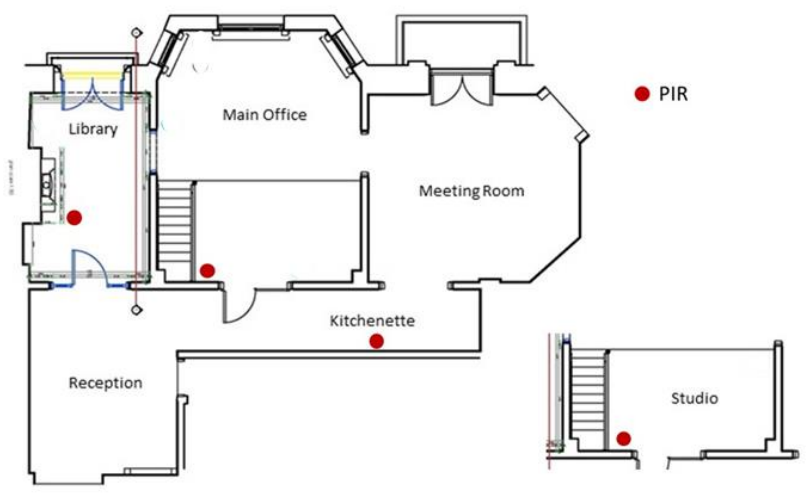

Fig3: Sensor places on floor plan

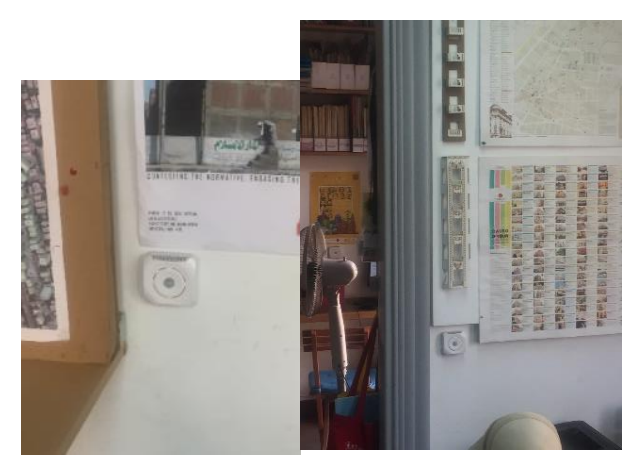

Fig4: Samples of the sensors installed

\subsection{POE}

Post-occupancy evaluation (POE) is a studying the current situation of a building occupied by residents, in order to analyze the current conditions and learn to improve them. The concept of POE was first introduced in the 1960's. This study focuses on hoe residents are satisfied with the building performance and their surrounding environment including the indoor environmental quality, thermal, visual, lighting and acoustic comfort. It also includes occupants' evaluation about functional aspects of the building such as spatial relations and comfort, HVAC efficiency, communications and other type of equipment efficacy, building circulation and accessibility, energy consumption and energy sources, etc. Since this study aims to evaluate thermal comfort level, the POE evaluation will only focus on occupants' satisfaction and comfort with the thermal environment. POE was chosen to be the second supportive method of evaluation due to several reasons:

- Feasibility

- Cost-efficient

- Time-efficient
- Quick method of evaluation

- Highly indicative and focuses on occupants as the main indicator

HEFCE et al. (2006) recognized POE as a process that can be applied to any type of building. This process comprises seven steps:

- Identify aim of the POE

- Decide on which approach

- Brief for the POE

- Plan the POE

- Carry out POE

- Report on findings

- Take action in response to findings.

The scope of this paper falls within POEs in which the occupants' subjective views about the physical environment of the workplace are measured and compared to actual thermal readings obtained from sensors installed. In addition, this research only included the first six steps of the POE seven-step process.

\subsection{Analysis and Findings}

The office consists of 20 occupants and they were all asked to answer the questionnaire subjectively. Occupants normally spend 8-12 hours in the office. All of the occupants of the office were desk based and the office arrangement consists of high-occupancy plan rooms. Respondents aged range from 20 to 40 years old. $65 \%$ are female while $35 \%$ are male respondents. The questionnaire was selfadministered and included occupants giving their evaluation of thermal comfort and humidity level several times during summer time; almost monthly. The Likert-Scale consists of 7 numerical nomenclatures indicating the responses given on occupant's thermal comfort based on their thermal sensation, which ranges from ' -3 ' to ' 3 '. Moreover, thermal comfort evaluation was carried out through analyzing data from the sensors for temperature and humidity respectively for each space. A sample of results was chosen to be the subject of comparison between results of POE conducted towards the end of July and data obtained from sensors for that same month. Respondents' evaluation of thermal comfort in July, 2017 is represented in figures 5 and 6. 


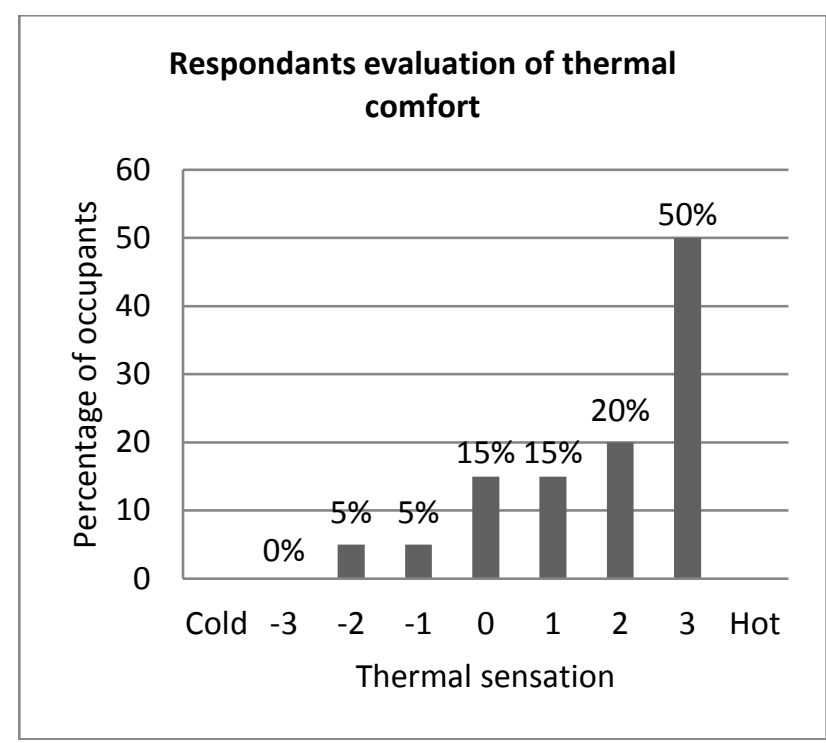

Fig5: Respondents' evaluation of thermal comfort in July, 2017

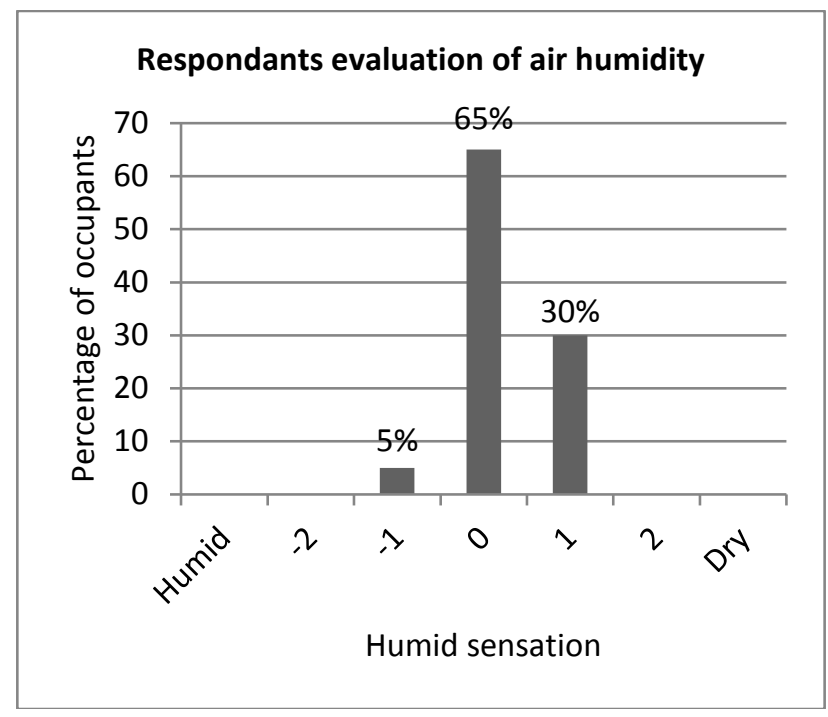

Fig6: Respondents' evaluation of air humidity in July, 2017

Based on results demonstrated in Figures 5 and 6, it is clear that $50 \%$ of the occupants feel discomfereted with the how hot the office gets in the summer. As for the humidity, $65 \%$ of the occupants have a neutral feeling about the humidity level in the office. Moreover, the questionnaire also included asking the occupants about their opinions with other aspects. Responses indicated that $50 \%$ of the occupants feel that the Library and Studio (which is located in the main office) are spaces with highest thermal discomfort level.

Figures 7 and 8 represent readings obtained from sensors for temperatures and humidity respectively.

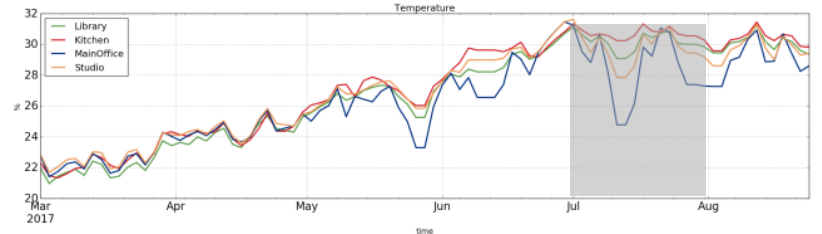

Fig 7: Daily average temperature from March till August, 2017

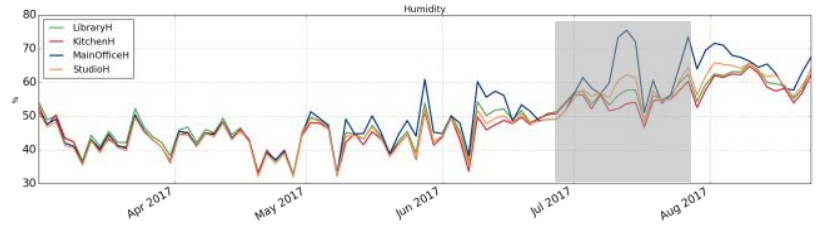

Fig.8: Daily average readings for humidity from March till August, 2017

The time slot highlighted represents the study sample chosen. When highlighted results were compared to occupant's responses, it was found that humidity levels were very high (reaching 70-80\%) which should have caused great discomfort for occupants. However, occupants did not experience great discomfort with the humid sensation according to their responses. Results also show great variations in readings between the different spaces. In addition, data extracted from sensors for plotting indicate presence of error in readings at times; unreasonable values or 0 values which were accordingly excluded from plotted data.

A psychometric chart was used to plot the data for monitoring thermal comfort where results were compared to the thermal comfort zone determined by ASHRAE Standard 55-2013 (Figures 9 to 12).

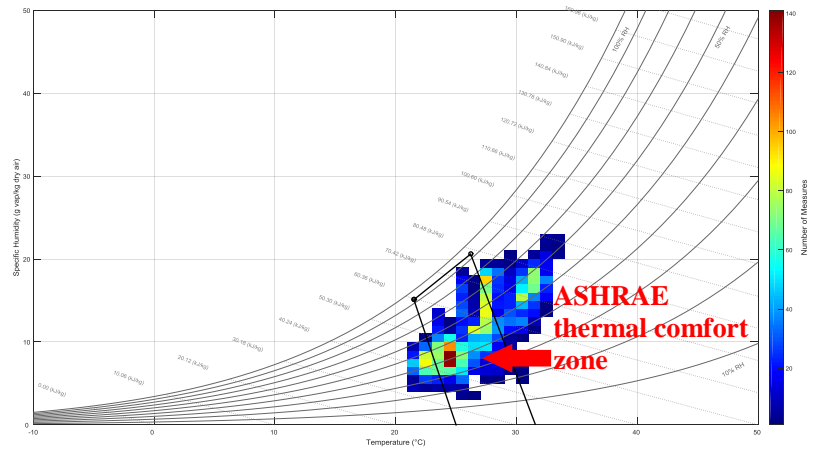

Fig.9: Monitoring of library space-data plotted on an hourly basis 


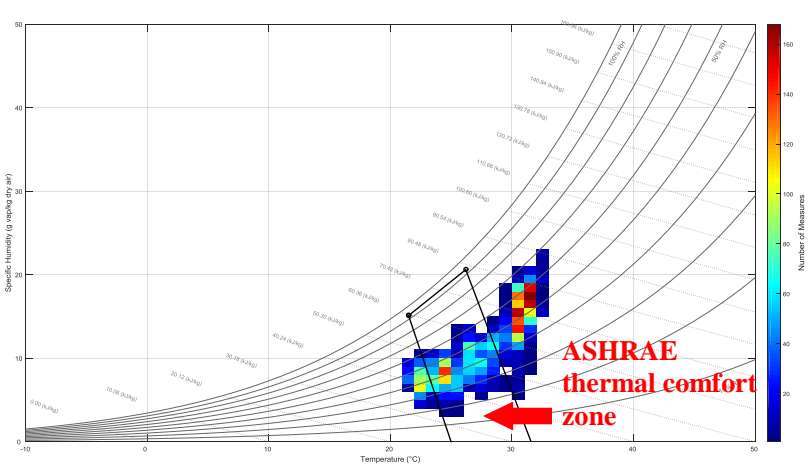

Fig.10: Monitoring of kitchen space-data plotted on an hourly basis

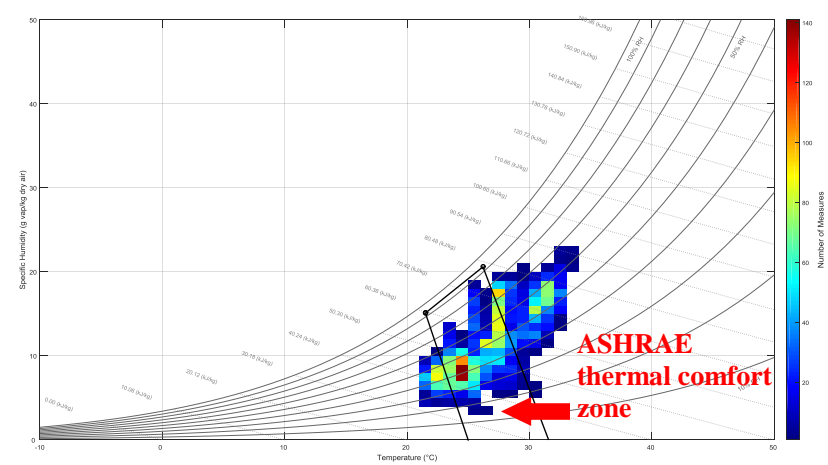

Fig.11: Monitoring of main office space-data plotted on an hourly basis

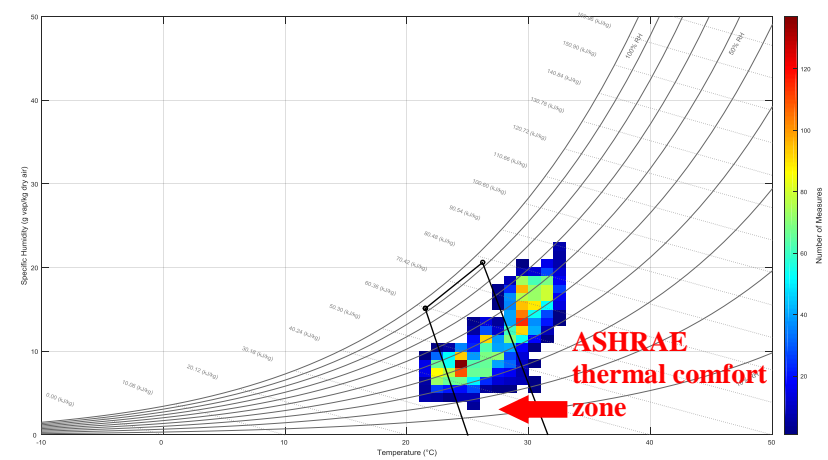

Fig.12: Monitoring of studio space-data plotted on an hourly basis

Based on the graphical analysis presented and results from the POE study, thermal comfort outcomes seem to be consistent for both evaluation methods. Thermal readings indicate high temperatures exceeding the comfort level which was verified by occupants' responses indicating sensation of discomfort with thermal level.

\section{Conclusion}

Thermal comfort evaluation has evolved a great deal with the help of smart sensing systems. However, the possibility of inaccurate data due to unclear barriers creates some difficulties. In this research, an in-field investigation methodology on thermal comfort was applied on an office space study sample in a heritage building. The research used two approaches for thermal evaluation including both the physical and human aspect. The first was measuring thermal parameters influencing comfort level using low-cost live-data sensors. The second was a POE oriented questionnaire survey obtaining occupants' satisfaction with thermal comfort. This study aimed at not only evaluating thermal comfort but using different approaches to it for the aim of comparing results and gaining perspective on the efficiency and accuracy of data provided by the sensing system. Since occupant satisfaction is a very important aspect of achieving sensation of comfort, POE should be considered an important and essential part of any thermal evaluation process. It is important to validate results of monitoring thermal comfort with occupants' views on their physical condition. Moreover, it provides a good insight on underlying variables that might be affecting thermal comfort levels.

The results of measurements obtained indicate that there is a problem with the data accuracy. Consequently, a few barriers were determined as a possibility behind inaccuracy of data. Such barriers are often in the form of technical barriers or barriers caused by the presence of environmental or physical barriers not taken into consideration. Predicted barriers causing data inaccuracies for the smart sensing system applied are shown in table 1 .

Table 1: Assumed barriers causing inaccuracy of data extracted from smart sensors

\begin{tabular}{|c|c|c|}
\hline \multicolumn{2}{|c|}{ Assumed Barriers } & Comments \\
\hline \multirow{3}{*}{ 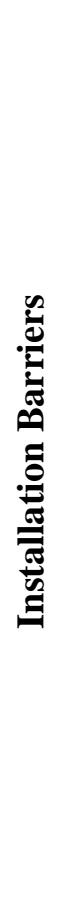 } & $\begin{array}{l}\text { Limitations in } \\
\text { location and } \\
\text { position of sensors } \\
\text { due to need of } \\
\text { proximity to } \\
\text { electrical plugs. }\end{array}$ & $\begin{array}{l}\text { This problem was } \\
\text { only found in sensors } \\
\text { that need electricity } \\
\text { to function. However } \\
\text { most of the sensors } \\
\text { work on batteries. }\end{array}$ \\
\hline & $\begin{array}{l}\text { Limitations } \\
\text { caused by office } \\
\text { furniture } \\
\text { distribution. }\end{array}$ & $\begin{array}{l}\text { Some of the furniture } \\
\text { in the office was } \\
\text { found to cause a } \\
\text { thermal barrier for } \\
\text { example computers. } \\
\text { Therefore selection } \\
\text { of PIR locations was } \\
\text { a difficult process as } \\
\text { the office was very } \\
\text { condensed. }\end{array}$ \\
\hline & $\begin{array}{l}\text { Inappropriate } \\
\text { sensor fittings } \\
\text { causing sensors to } \\
\text { sometimes fall out } \\
\text { of } \quad \text { position }\end{array}$ & \\
\hline
\end{tabular}




\begin{tabular}{|c|c|c|}
\hline & $\begin{array}{l}\text { possibly causing } \\
\text { damage. }\end{array}$ & \\
\hline \multirow{4}{*}{ 包 } & $\begin{array}{l}\text { Manufacturing } \\
\text { errors }\end{array}$ & $\begin{array}{l}\text { Some of the PIRs } \\
\text { were found to have a } \\
\text { manufacturing error } \\
\text { where readings for } \\
\text { humidity showed a } \\
\text { usual pattern that } \\
\text { mimics readings for } \\
\text { temperatures. }\end{array}$ \\
\hline & $\begin{array}{l}\text { Failure in internet } \\
\text { connectivity }\end{array}$ & $\begin{array}{l}\text { Internet failures } \\
\text { cause data not to be } \\
\text { sent to website for } \\
\text { analysis. Such data } \\
\text { have to be extracted } \\
\text { directly from the } \\
\text { Zigbee Dongle. }\end{array}$ \\
\hline & Power cuts & $\begin{array}{l}\text { Frequent power cuts } \\
\text { causes data loss, in } \\
\text { addition monitoring } \\
\text { unit needs to be } \\
\text { restarted directly } \\
\text { afterwards to } \\
\text { function properly. }\end{array}$ \\
\hline & $\begin{array}{l}\text { Accidental } \\
\text { unplugging of } \\
\text { sensors or } \\
\text { monitoring unit }\end{array}$ & \\
\hline
\end{tabular}

References:

[1] F. J. R. Martinez, M. A. Chicote, A. V. Penalver, A. T. Gonzalez and E. V. Gomez, "Indoor air quality and thermal comfort evaluation in a Spanish modern low-energy office with thermally activated building systems," Science and Technology for the Built Environment, pp. 1091-1099, 2015.

[2] L. Yang, H. Yan and J. C. Lam, "Thermal comfort and building energy consumption implications - A review," ELSEVIER: Applied Energy, pp. 164-173, 2014.
[3] R. F. Rupp, N. G. Vásquez and R. Lamberts, "A review of human thermal comfort in the built environment," 2015.

[4] L. Barrios and W. Kleiminger, "The Comfstat - Automatically sensing thermal comfort for smart thermostats," in 2017 IEEE International Conference on Pervasive Computing and Communications, Kona, HI, USA, 2017.

[5] ASHRAE, "Thermal environmental conditions for human occupancy," no. ANSI/ASHRAE Standard 55-2010, 2010.

[6] W. J. Fisk, "Review of some effects of climate change on indoor environmental quality and health and associated no-regrets mitigation measures," Building and Environment, pp. 70-80, 2015.

[7] W. W. Nazaroff, "Exploring the consequences of climate change for indoor air quality," Environmental Research Letters, 2013.

[8] T. Brennan, "Climate Change: Impact on Building Indoor Environmental," in 14th Annual Green Building Conference, New York, 2016.

[9] M. J. Holmes and J. N. Hacker, "Climate change, thermal comfort and energy: Meeting the design challenges of the $21 \mathrm{st}$ century," ELSEVIER: Energy and Buildings, pp. 802-814, 2007. 
Contribution of individual authors to the creation of a scientific article (ghostwriting policy)

Esraa Abdelhady carried out the measurements and analysis of the case study

Gehan Nagy organised and edited the paper's sections

\section{Sources of funding for research presented in a scientific article or scientific article itself}

This paper is part of the publications of a wide research project. The project is entitled 'Heritage Building Information Modelling and Smart Heritage Building Performance Measurements for Sustainability', ID 18443 and is funded by the Science and Technology Development Fund (STDF). The two-year project is adopted by the British University in Egypt and was initiated in February 2016. The authors would like to acknowledge the financial funding and support provided by the STDF and the British Council. The authors gratefully acknowledge the help and support of the project partners; Richard Fitton and Alex Marshall from University of Salford, Lamine Mahdjoubi and Ammar Al Zaatreh from University of West of England (UWE). Last but not least, the authors would like to acknowledge the efforts and of Omar Nagaty founder of CLUSTER Office Egypt and his whole team in supporting the research and cooperating in providing the space for and requirements of the study.

\section{Creative Commons Attribution}

\section{License 4.0 (Attribution 4.0}

\section{International, CC BY 4.0)}

This article is published under the terms of the Creative Commons Attribution License 4.0 https://creativecommons.org/licenses/by/4.0/deed.en $\underline{\underline{U S}}$ 